\title{
THE NATURE AND SIGNIFICANCE OF NETWORK INTERACTIONS FOR BUSINESS PERFORMANCE AND EXPORTING TO MEXICO: AN ANALYSIS OF HIGH-TECHNOLOGY FIRMS IN TEXAS
}

\author{
Niles Hansen and Elsie Echeverri-Carroll*
}

\begin{abstract}
This article utilizes survey data from high technology firms in Texas to analyze the location of their interfirm cooperative contacts and the importance of these contacts for their business success in general and for exporting to Mexico in particular. A literature review of the nature of collaborative firm networks in both Europe and the United States is followed by an empirical analysis of how local, national and international interfirm contacts differ between manufacturing and service establishments, between independent and branch establishments, and between large firms and small and medium-size enterprises (SMEs). Policy implications of the results are considered in the concluding summary.
\end{abstract}

\section{INTRODUCTION}

This article addresses a number of issues related to potentially expanding export opportunities offered by the North American Free Trade Agreement, with particular attention given to small and medium-size enterprises (SMEs). European evidence discussed in the next section particularly suggests that in regions where exports have grown substantially, such expansion has been promoted more by interfirm information flows than by government-organized information services. The empirical part of this article, which uses data obtained from high technology firms in Texas, analyzes the relative importance of different types of interfirm network contacts for business success in general and for exporting to Mexico in particular. ${ }^{1}$

Another significant issue raised in the literature review of collaboration networks in Europe and the United States is the degree to which interfirm cooperation is localized or widely dispersed geographically. The empirical evidence presented here indicates that interfirm relations are primarily non-local in nature. The implications for policy are that efforts to promote exports should give greater attention to encouraging interfirm cooperation, with emphasis on collaboration with non-local enterprises, including foreign firms.

\footnotetext{
*L.G. Denman, Jr., Regents Professor, Department of Economics, University of Texas at Austin; and Head, Economic Development Program, Bureau of Business Research, School of Business, University of Texas at Austin. Research for this article was funded by the Center for the Study of Western Hemispheric Trade. Valuable research assistance was provided by Lynn Hunnicutt. The authors also gratefully acknowledge the helpful comments of anonymous referees.
} 


\section{COLLABORATIVE NETWORKS IN EUROPE}

Attempts to explain geographic differences in the creation of new firms and economic activities by using variables reflecting potentially supporting activities have met with very limited success. Such variables have included size of place, access to capital, industry mix, labor force education and skills, and the presence of research centers, airports, and local cultural, residential and climate amenities. These approaches fail to explain the implementation of development processes, and there is no assurance that most of the potentially supporting activities are actually being used by local firms. How entrepreneurs respond to these factors depends upon how they interact with other firms, entrepreneurs, and local resources. As Malecki (1994) points out, this is an issue that can best be addressed through the analysis of networks, which constitute the milieu within which SMEs operate. Interpersonal networks for information flows are central to the transfer of knowledge among persons, firms, and regions; and most innovation-stimulating information flows through informal channels.

Although it is difficult to identify the places where entrepreneurs are likely to emerge, recent European research on the nature of "innovative milieu" has shifted emphasis away from static analyses of supporting locational factors in favor of analyses of dynamic processes with respect to behavior patterns, the accumulation and transmission of technical knowledge, and the standards and values connected with economic activity (Maillat 1993). An innovative milieu uses its economic, cultural and technological structures to organize and coordinate its resources in new production combinations. Because innovation is a complex and uncertain process, it is implemented collectively in the form of innovation networks. A network presupposes a system of evolving long-term relations among the various players, based on mutual knowledge, trust and reciprocity. The network-type organization is a repository of a collective know-how greater than the sum of the individual players' know-how, which allows collective learning processes to develop. An innovative milieu is also open to the outside world for information and resources.

Innovative regional milieux in Europe have in fact been characterized by network economies. As Cappellin and Nijkamp (1990), point out, "the policy implications of a network economy are far reaching: instead of focusing attention on nodes (e.g., locations, actors), one has to look at edges (e.g., interaction patterns or transfer mechanisms for knowledge)." Thus, for example, if one looks only at an individual SME, it could readily be supposed that it could not achieve economies of scale in methods of production. However, as Bull, Pitt and Szarka (1991) argue, SMEs as a group can achieve economies of scale if they participate in a division of labor that is both localized and task specialized. In this context, 
SMEs would pursue niche strategies not only with respect to customers or products, but also with respect to methods of production. However, niche strategies concerning production would not be carried out in isolation by autonomous entities, but rather as part of an interrelated local production complex. Policy measures should not be directed toward the well-being of a few successful firms, as has been proposed in England; they should instead support and enhance the competitiveness of the area as a whole because the dynamism and growth of the area "depends on the success of individual firms which are part of it only insofar as these are able to contribute to each other's competitiveness" (Bull, Pitt and Szarka 1990; emphasis theirs.)

In view of the increasing internationalization of economic activity, it is noteworthy that SMEs in general seem to make little use of formalized export information services, but rather rely on experimental information gathering (Christensen 1990). Government information services tend to provide general information on such matters as prices and documentation procedures, whereas new exporters are more interested in specific transaction-creating opportunities involving exhibits, fairs, distribution channels, agents and market contacts. New exporters in practice are more intent on finding direct relations with clients through informal networking than on planning formal market intelligence systems. In other words, direct contacts and personal relationships induce marketing research, rather than the converse. However, the internationalization process of SMEs should be seen not only in terms of a firm and market interface, but also in terms of a process of mobilization of the external resources of the milieu, that is, the ability of the SME to find and involve suppliers, consultants, agents and brokers. Thus, Christensen maintains that in contrast to the model of SME exporting where the know-how leads to the know-who, the know-who is the key to know-how for the entrepreneurial exporter.

Among Europe's innovative regional milieux, the Jutland Peninsula of Denmark (Hansen 1991; Illeris 1992) and the Third Italy (Brusco 1986; Garofoli 1991) have received particular notice. Because it would be beyond the scope of this study to review the origins and evolution of these areas, the present discussion is limited to observations concerning the export behavior of their SMEs, in order to ascertain possible implications for SME exporting elsewhere.

In Denmark, 98 percent of total private sector employees work in SMEs, by far the highest proportion in Europe (Hansen 1991). Moreover, Denmark has one of the most export-oriented economies in the western world. Nevertheless, there is hardly any district in the country where manufacturers are able to organize an entire value-added chain for a product that is eventually exported. Instead, each individual firm in a location relates to a complex network of regional, national and international firms. Even if the producer for the final market subcontracts to other 
regional firms, they in turn obtain their inputs from regional, national and international sources. By using its specialized assets flexibly for different customers, the individual SME participates through indirect linkages in a wide network of valueadded chains (Kristensen 1994).

Most of the external relations of Danish SMEs are not formalized through contracts or "strategic alliances," but are rather maintained through personal relations with specific individuals in other enterprises, relations that are governed essentially by trust and mutual reciprocity. Moreover, in western Denmark, where individual entrepreneurship is particularly valued by the community as a whole, SMEs tend to avoid the use of formal associations and institutions outside of their immediate control because they suspect that they would lose more to bureaucratic games than they would gain by an institutionalization of their private informal networking (Kristensen 1994). While the heterogeneous networking that takes place in Denmark may make it difficult for SMEs to formulate specific long-term exporting strategies, the informal system of cooperation has been conducive to flexibility, learning, and success.

No model of flexible SME manufacturing networks has attracted as much attention as that of the Third Italy, a term used to distinguish it from the older Milan-Turin-Genoa industrial triangle in the northwest and from the less developed area south of Rome. Within the Third Italy there is a pronounced tendency for localities to specialize in the production of a range of related goods. In Tuscany, for example, cloth is made at Prato and ceramics at Sesto and Montelupo; in Emilia-Romagna, knitwear is made at Carpi, ceramic tiles at Sassuolo, motorcycles and automatic machines at Bologna, and farm machinery at Reggio Emilia; in the Marche, shoes are manufactured near Ancona; and in the vicinity of Venice ceramics, furniture and sport shoes are produced. Some industrial districts in the Third Italy are backward, pay low wages, have few exports, and are highly exposed to competition from newly industrializing countries. However, many are innovative, technologically advanced, and successful in the international marketplace. It is of course the latter type that has attracted international attention.

As in the Danish case, there are many interdependencies among SMEs in the industrial districts of the Third Italy. However, SMEs in the Italian districts tend to be associations organized around the realization of local full value-added chains. Cooperation occurs primarily along the vertical dimension of the chain; that is, each individual SME has a specialized role in a process that contains most of the steps required to turn raw materials into finished goods. In contrast, competition occurs among SMEs at similar levels of the production chain (Piore and Sabel 1983).

In the Third Italy, SMEs are heavily engaged in exporting, and in the most successful Italian export sectors, such as consumer durables, they are at the lead- 
ing edge (Bonaccorsi 1992). The function of coordinating the overall production and marketing process has been fulfilled by agents (the prototype being the impannatori of Prato) who actively link local groups of SMEs with fluctuating international demand patterns. These agents, heirs to the mercantilist traditions of the medieval Italian cities, are also involved in the design and redesign of products in response to specialized demands. By continuously interfacing the short-run situations in external markets with the internal situations of industrial districts, they "extract from the local cultural stock (which includes technologies, but much more besides) all the new ideas it contains. By doing so, they guide and stimulate the combinatorial instinct of all the other agents in the district" (Becattini 1991).

Just as studying the attributes of locations may not yield an adequate understanding of the process of new firm creation, so studying the internal attributes of firms (their sales, employment, research and development, technological level, marketing staff, etc.) may not be very instructive in explaining their export behavior and performance. Instead of using their own internal resources for exporting tasks, SMEs can delegate such tasks to other operators.

Bonaccorsi (1992) points out that access to external resources has in fact played a major role in the internationalization processes of Italian SMEs. Italian empirical research does not support the prevalent notion that economies of scale in export management are important. Italian SMEs have found that it is not difficult to participate in exporting, and that exporting consumes fewer of their resources than attempts at product diversification or efforts to sell more widely in the domestic market. Moreover, the fact that they have been successful in foreign markets has been less a result of their marketing skills than of having the right mix of product quality, price, flexibility, and responsiveness to consumer demand. Decision-making in these regards has been facilitated by the collective experiences of the group of local SMEs to which the firm belongs. The internationalization process has thus been expedited in many instances by indirect imitative behavior, but even more so by information on problems and opportunities in foreign markets obtained through direct personal relationships and based on trust and reciprocity.

\section{COLLABORATIVE NETWORKS IN THE UNITED STATES}

In his analysis of international competitive advantage, Porter (1990) maintains that innovation and information diffusion are facilitated by the geographic concentration of rivals in regions within nations. Among the mechanisms that promote interchange within clusters of firms are norms of behavior that create trust, which in turn mitigates perceived differences in economic interest among 
networked enterprises. However, he argues that such mechanisms are generally relatively weak in the United States. Malecki (1991) also finds that local production systems such as those found in the Third Italy are uncommon in the United States. Lorenz (1990) too reaches a similar conclusion on the ground that the social norms of U. S.. producers typically do not motivate cooperation based on trust and reciprocity; the successes of other firms tend to be regarded as threats to one's own success in a zero-sum game world.

In contrast, there is also evidence that cooperation does co-exist with competition in some U. S. industries. For example, Porter remarks that innovative interchanges seem to work best in two of the most internationally successful sectors, computing and health care, where "scientific ties often overcome the natural reticence of American managers toward interchange" (Porter 1990). Saxenian (1994) maintains that Silicon Valley is a U. S. counterpart to the innovative industrial districts of Europe and that this region's success owes as much to networks of relationships as to the efforts of individual enterprises. She argues that geographic proximity has promoted the frequent interaction and personal trust required to maintain these networks. Similarly, Butler and Hansen (1991) have shown that both broad social and interorganizational strategic networks have been important to successful start-ups and ongoing competitive advantage in the Washington wine industry.

Other studies of U.S. networks have found that cooperation takes place over wide areas rather than locally. For example, members of networks of SMEs in the petroleum products distribution sector have gained competitive advantages as a result of collaboration sustained by trust, understanding, and continuity (Upton 1995). However, these groups are composed of company presidents who are located in widely separated cities. Angel (1995) found that about one-third of a random sample of 495 manufacturers in the chemical, instruments, and electronics industries participate in some form of collaborative technology development activity with customers, suppliers or other firms. Enterprises thus engaged are on average the more innovative firms within an industry. Interfirm collaboration is more prevalent among large firms than small firms, and among establishments serving international markets. However, only a small proportion of collaborative partnerships are with local firms; most are national and international in scope. The local benefits from collaboration therefore come mainly from the strengthened performance of participating local firms, rather than from the emergence of a localized network among manufacturers, customers and suppliers. 


\section{MEXICAN DEMAND FOR TEXAS EXPORTS}

The North American Free Trade Agreement (NAFTA), which went into effect at the beginning of 1994, provides for continual tariff reductions over the next fifteen years, but the Mexican Government has in fact been reducing trade barriers for nearly a decade. This trade liberalization has been especially beneficial to Texas, whose exports to Mexico in 1992 amounted to $\$ 18.8$ billion, or 46 percent of the U. S. total. Texas' merchandise exports to Mexico, which account for nearly 5 percent of the gross state product, have almost tripled in inflation-adjusted value since 1987. Moreover, all of the recent growth in high technology manufacturing in Texas can be explained by exports to Mexico (George and Taylor 1995).

Although Mexico has been experiencing another of its periodic economic crises, in the long run it is counting on NAFTA to create expanded employment and exports, which in turn will enable Mexico to import the capital goods and technologies required to make its economy increasingly productive and competitive. Empirical evidence indicates that SMEs are more likely to be exporters if they produce in technologically-advanced sectors (Erickson, Friedman and Lowe 1995). Thus, recent signs of recovery in the Mexican economy bode well for such enterprises in Texas.

\section{NETWORKS AND EXPORTING: A TEXAS CASE STUDY}

Survey research was undertaken to address numerous issues suggested by the foregoing literature review and the Texas-Mexico context. In particular, the survey instrument was designed to obtain information concerning the following questions. How does the importance of participation in various types of local and national networking differ between manufacturing and service establishments, between independent and branch establishments, and between large firms and SMEs? How important is participation in these regards for establishments that export to Mexico? How does participation in these regards differ between firms that export to Mexico and non-exporters? How important are interactions between establishments that export to Mexico and Mexican firms? How important for exporting establishments are social, family and cultural relations in Mexico? And to what degree does participation in various types of networking depend on the importance of exporters being established in U.S. markets?

Data concerning the importance of various types of networking interactions were obtained from a mail survey questionnaire sent to high-technology firms in the metropolitan areas of Dallas-Ft. Worth, Houston, Austin and San Antonio. Questionnaires were sent to firms in sectors known to have particularly high 
proportions of firms that export. In manufacturing, these included firms in 28 four-digit SIC-code subsectors within the industrial machinery and equipment (SIC 35), electronics (SIC 36), and instruments and related products (SIC 38) sectors. In services, these included computers (SIC 737), engineering and architecture (SIC 871), management and public relations (SIC 874), and research, development and testing (SIC 873). Firms in these activities were identified with the assistance of District Export Councils in Dallas and San Antonio, the Austin Software Council, and international business directories. Usable responses were obtained from 178 firms, which represented a response rate of approximately 20 percent.

Table 1 presents data on the degree of importance given to four types of networking interactions within the United States by establishments with various characteristics. The respondents were asked to indicate the relative importance of the types of interactions on a scale from 1 (not important) to 5 (very important). They were asked, "In general, to what extent has your business benefitted from the following types of contacts, which may be formal or informal?" The four types were (1) business contacts with local firms in the same line of business activity; (2) local non-business, social or cultural networks; (3) local business contacts with firms in other business activities; and (4) business contacts with firms in the same business activity located in the rest of the United States. The last will be referred to hereinafter as non-local interactions or contacts.

For the entire set of 178 establishments, contacts with firms in the same activity were most important, with non-local contacts (3.52) being more important than local contacts (2.96). In terms of type of production, local non-business contacts were the least important for both manufacturing and service establishments, but they were significantly greater at the .05 level for service establishments. Similarly, local interactions with firms in other activities were significantly greater for service establishments. In contrast, non-local contacts were significantly greater for manufacturing establishments at the .10 level. Thus, while non-local linkages were the most important for both groups, they were relatively more important for manufacturers. Local linkages were relatively more important for service establishments, presumably because of their greater orientation to the local market.

In terms of type of establishment, independent firms and branch establishments had overall response patterns similar to the total sample. The exception was non-local interactions, which were significantly higher for independent firms at the .05 level. Nevertheless, non-local interactions were still the most prevalent type of networking for branch establishments.

The employment size categories shown in Table 1 consist of large firms with over 100 employees and SMEs. Non-local contacts were the most important for 

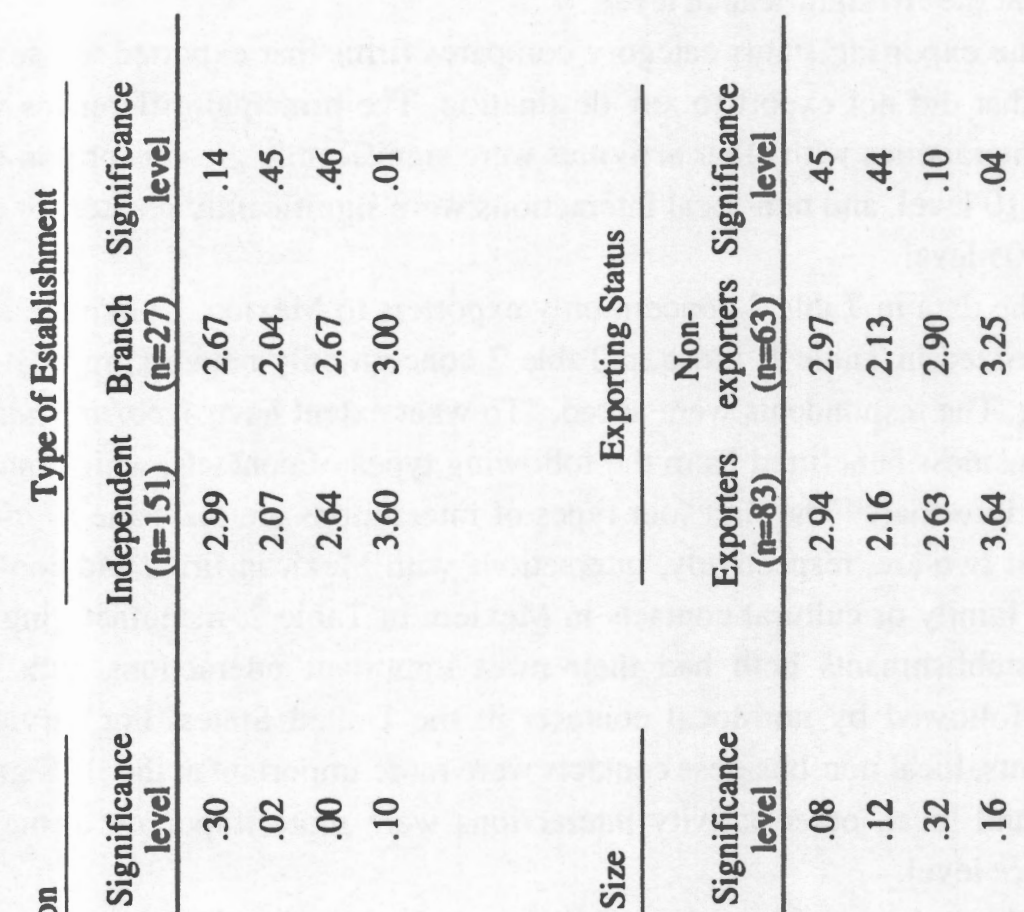
both groups, but local contacts with the same activity were more important for SMEs at the .10 significance level.

The exporting status category compares firms that exported to Mexico with firms that did not export to any destination. The principal differences were that local interactions with other activities were significantly greater for non-exporters at the .10 level, and non-local interactions were significantly greater for exporters at the .05 level.

The data in Table 2 concern only exporters to Mexico. Unlike the responses summarized in Table 1, those in Table 2 concern only networking related to exporting. The respondents were asked, "To what extent have exporting activities of your business benefitted from the following types of contacts, which may be formal or informal?" The first four types of interactions are the same as in Table 1. The last two are, respectively, interactions with Mexican firms and non-business social, family or cultural contacts in Mexico. In Table 2, manufacturing and service establishments both had their most important interactions with Mexican firms, followed by non-local contacts in the United States. For service establishments, local non-business contacts were more important at the .10 significance level; and local, other activity interactions were more important at the .05 significance level.

Independent and branch establishments both had their most important contacts with Mexican firms, but such interactions were significantly more important for branches at the .05 level. For both groups, U.S. non-local contacts were second in importance, but in this case such interactions were significantly more important for independent firms at the .05 level. Independent firms had significantly more important interactions than did branches for all three types of local linkages.

Both large establishments and SMEs had their most important interactions with Mexican firms, and there was no significant difference in this regard. Large establishments had Mexican non-business interactions that were greater than those for SMEs at the .05 significance level. The importance of local, same activity contacts was significantly greater for SMEs at the .05 level.

The final set of results in Table 2 contrasts respondents who held that it is important or very important to be well-established in U.S. markets before exporting with respondents who felt this was not important. The former group have the highest values for all types of interactions, and for four types the differences were significant at the .05 level. For both groups, interactions with Mexican firms were the most important, followed by non-local contacts in the United States.

The data in Table 3 concern reasons why non-exporting establishments do not export, broken down by those that want to export and those that do not. Only four respondents in the last category were simply not interested in exporting. 


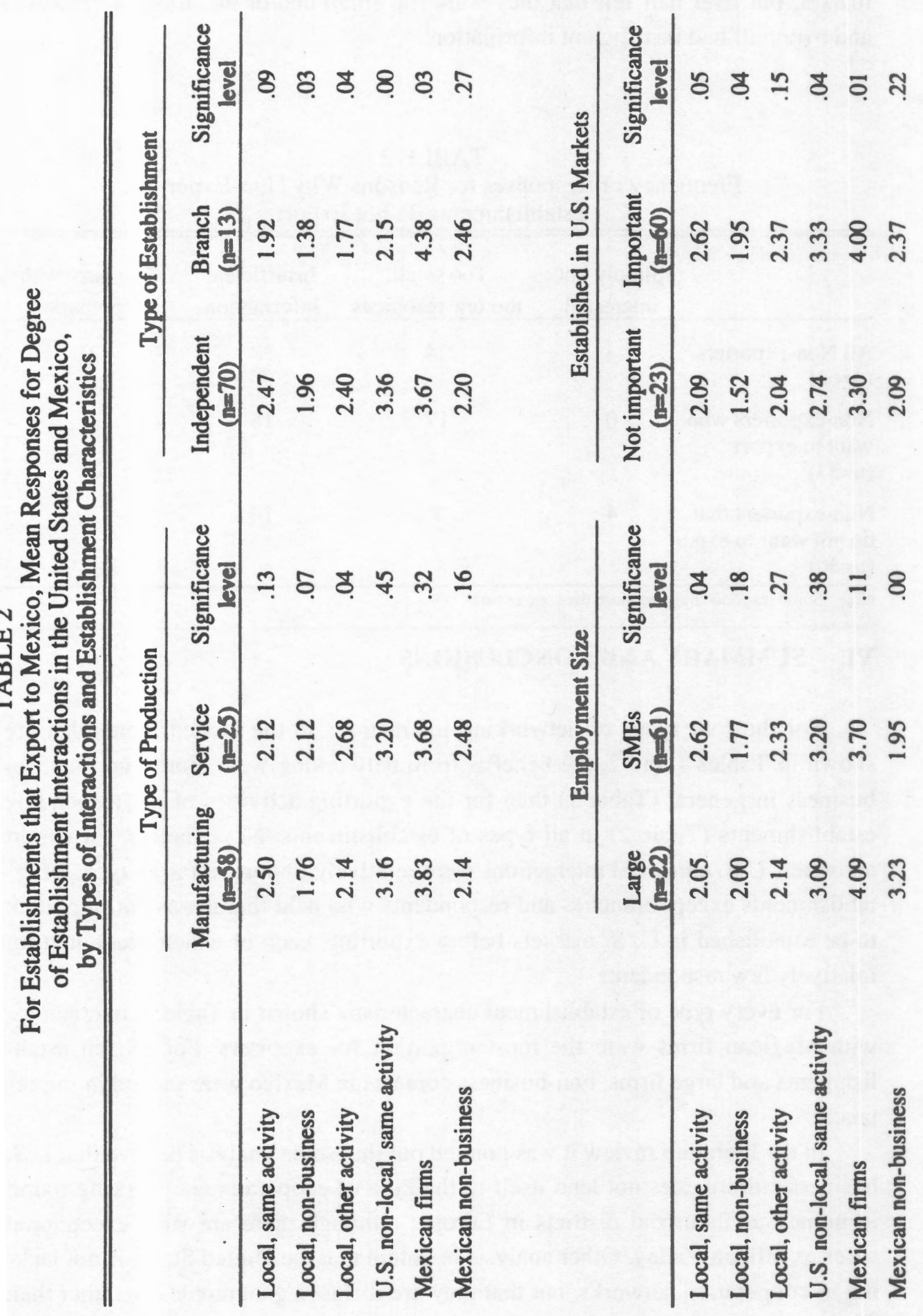


Among the respondents that wanted to export, a third were too busy with the U.S. market, but over half felt that they were too small and/or had too few resources and over half had insufficient information.

TABLE 3

Frequency of Responses for Reasons Why Non-Exporting Establishments do not Export

\begin{tabular}{lcccc}
\hline \hline & $\begin{array}{c}\text { Simply not } \\
\text { interested }\end{array}$ & $\begin{array}{c}\text { Too small; } \\
\text { too few resources }\end{array}$ & $\begin{array}{c}\text { Insufficient } \\
\text { information }\end{array}$ & $\begin{array}{c}\text { Too busy with } \\
\text { U.S. market }\end{array}$ \\
\hline $\begin{array}{l}\text { All Non-exporters } \\
\text { (n=63) }\end{array}$ & 4 & 24 & 28 & 21 \\
$\begin{array}{l}\text { Non-exporters who } \\
\text { want to export } \\
\text { (n=33) }\end{array}$ & 0 & 17 & 18 & 11 \\
$\begin{array}{l}\text { Non-exporters that } \\
\text { do not want to export } \\
\text { (n=30) }\end{array}$ & 4 & 7 & 10 & 10 \\
\hline \begin{tabular}{l} 
Note: Some respondents gave more than one reason \\
\hline
\end{tabular}
\end{tabular}

\section{SUMMARY AND CONCLUSIONS}

For the four types of networking interactions in the United States that are shown in Tables 1 and 2, the benefits from networking were more important for business in general (Table 1) than for the exporting activities of the responding establishments (Table 2) in all types of establishments. Nevertheless, for export activities, U.S. non-local interactions were relatively important for all types of establishments except branches and respondents who held that it was not important to be established in U. S. markets before exporting, each of which accounted for relatively few respondents.

For every type of establishment characteristic shown in Table 2, interactions with Mexican firms were the most important for exporters. For branch establishments and large firms, non-business contacts in Mexico were second in importance.

In the literature review it was pointed out that some analysts believe that U.S. business culture does not lend itself to the kind of cooperative networking found in numerous industrial districts in Europe, although there are such exceptional cases as Silicon Valley. Other analysts maintain that the United States is not lacking in cooperative networks, but that they are diffused geographically rather than localized primarily within a local "innovative milieu." The results of the present 
study support this position. U.S. non-local networks were of most benefit for business in general for all types of establishments (Table 1), and such networks were also the most important in benefiting export activities, with the exception of (nonlocal) interactions with Mexican firms and, in two cases, with non-business Mexican interactions (Table 2).

In this study, 67 percent of the large-firm respondents exported to Mexico, but only 42 percent of the SMEs did so. However, there were no significant differences between these two groups with respect to the importance of non-local U.S. linkages for business success in general or with respect to the importance for exporting success of linkages with both non-local U.S. firms and Mexican firms.

Maillat (1990) has argued that, given the importance of innovation diffusion to regional development, policies in this regard should give more attention to the promotion of interfirm cooperation rather than to specific forms of assistance to individual firms. Angel (1995) has similarly maintained that policies intended to aid SMEs should highlight interfirm cooperation as an important element of technology development practice. Furthermore, such cooperation should be not only local in nature, but should also emphasize collaboration with non-local firms, including foreign firms. The evidence presented here suggests that these policy proposals could be fruitfully extended to the promotion of innovative non-local domestic and foreign networking that would enhance opportunities for exporting, especially for SMEs that would like to export but lack sufficient information.

\section{ENDNOTE}

1. We do not discuss the precise nature of the interfirm contacts of the surveyed establishments because this would have required in-depth interviews with the respondents. One of the authors has done previous research in the United States and Europe similar to that discussed in the present article, but with numerous additional in-depth interviews concerning the nature and significance of the respondents' collaborative networks. This approach yielded rich information, but the stories told were extremely heterogeneous. The articles published from these research efforts could not include the variety of experiences because it would require a book format to do justice to the myriad types of interfirm interactions that take place. Thus, the present study was deliberately limited to asking respondents about the location of their interfirm cooperative interactions and the importance of these contacts for their businesses in general as well as for exporting activities. This article should be viewed as a modest attempt to shed light on these issues. 


\section{REFERENCES}

Angel, David P. Interfirm Collaboration in Technology Development. Washington, D.C.: Economic Development Administration, U.S. Department of Commerce, 1995.

Becattini, Giacomo. "The Industrial District as a Creative Milieu." In Georges Benko and Mick Dunford (eds.). Industrial Change and Regional Development. London: Belhaven Press, 1991.

Bonaccorsi, Andrea. "On the Relationship Between Firm Size and Export Intensity." Journal of International Business Studies 4 (1992): 605-35.

Brusco, Sebastiano. "Small Firms and Italian Districts: The Experience of Italy."

In David Keeble and Egbert Wever (eds.). New Firms and Regional Development in Europe. London: Croom Helm, 1986.

Bull, Anna Cento, Martyn Pitt, and Joseph Szarka. "Small Firms and Industrial Districts, Structural Explanations of Small Firm Viability in Three Countries." Entrepreneurship and Regional Development 3 (1991): 83-99.

Butler, John E., and Gary S. Hansen. "Network Evolution, Entrepreneurial Success, and Regional Development." Entrepreneurship and Regional Development 3 (1991): 1-16.

Cappellin, R., and P. Nijkamp. "The Role of Space in Technological Change." In Riccardo Cappellin and Peter Nijkamp (eds.). The Spatial Context of Technological Development. Aldershot, England: Avebury, 1990.

Christensen, Poul Rind. "The Small and Medium-Sized Exporters' Squeeze." Entrepreneurship and Regional Development 3 (1991): 49-65.

Erickson, Rodney A., Susan W. Friedman, and Samuel X. Lowe. State Industrial Exports, Export Promotion Programs, and Exporter Targeting. Washington, D.C.: Economic Development Administration, U.S. Department of Commerce, 1995.

Garofoli, Givacchino. "The Italian Model of Spatial Development in the 1970's and 1980's" In Georges Benko and Mick Dunford (ed.). Industrial Change and Regional Development: The Transformation of New Industrial Spaces. London: Belhaven, 1991.

George, Kelly A., and Lori L. Taylor. "The Role of Merchandise Exports to Mexico in the Pattern of Texas Employment." Federal Reserve Bank of Dallas Economic Review, First quarter (1995): 22-30.

Hansen, Niles. "Factories in Danish Fields: How High-Wage, Flexible Production has Succeeded in Peripheral Jutland." International Regional Science Review 14 (1991): 109-32.

Illeris, Sven. "The Herning-Ikast Textile Industry: An Industrial District in West Jutland." Entrepreneurship and Regional Development 4 (1992): 73-84. 
Kristensen, Peer Hull. "Spectator Communities and Entrepreneurial Districts." Entrepreneurship and Regional Development 6 (1994): 177-98.

Lorenz, Edward H. "Trust, Community and Flexibility: Toward a Theory of Industrial Districts." Unpublished paper, University of Notre Dame, 1990.

Maillat, Denis. "Territorial Development, Milieu and Regional Policy." Working paper no. 9306, Institut de Recherches Economiques et Régionales, University of Neuchâtel, Switzerland, 1990.

Malecki, Edward J. Technology and Economic Development. New York: John Wiley and Sons, 1991.

Malecki, Edward J. "Entrepreneurship in Regional and Local Development." International Regional Science Review 16 (1994): 119-53.

Piore, Michael J., and Charles F. Sabel. "Italian Small Business Development: Lessons for U. S. Industrial Policy." In John Zysman and Laura Tyson (eds.). American Industry in International Competition. Ithaca: Cornell University Press, 1983.

Porter, Michael E. The Competitive Advantage of Nations. New York: The Free Press, 1990.

Saxenian, Anna Lee. Regional Advantage: Culture and Competition in Silicon Valley and Route 128. Cambridge: Harvard University Press, 1994.

Upton, Howard. "Peerless Advice From Small-Business Peers." Wall Street Journal, May 8, P. A14, 1995. 